\title{
Biographical Explorations through Creative Work
}

\author{
Heather McLeod, Memorial University \\ hmcleod@mun.ca \\ Morgan Gardner, Memorial University \\ mgardner@mun.ca \\ Elizabeth Yeoman, Memorial University \\ eyeoman@mun.ca
}

\begin{abstract}
We explore our teaching of Biographical Explorations of Teaching and Learning, a Curriculum and Instruction Masters course in the Faculty of Education at Memorial University in which we develop creative and imaginative thinking and learning amongst educators. We invite students into a multi-modal exploration of their lives as teachers and learners via readings, visual art, drama, music, literary writing, and media pieces that explore themes in teaching and learning. Students think critically about how narratives work within personal/professional and societal cultural contexts. They learn about and engage in creative ways of telling a story. In this paper we critically reflect on the affordances and challenges of this approach to arts-informed critical graduate pedagogy.
\end{abstract}

Keywords: Creative Narratives; Arts Curriculum and Instruction; Arts-informed Pedagogy; Critical Graduate Pedagogy

$\mathrm{W}$ e are three professors in the Education Faculty at Memorial University in St. John's, Newfoundland, Canada. In this paper, we explore our teaching of Biographical Explorations of Teaching and Learning, a Curriculum and Instruction Masters course. We develop creative and imaginative thinking and learning amongst educators through encouraging course participants to reflect on their lives as teachers and learners through reading, viewing and listening to a range of creative works (music, visual art, drama, literary writing and media pieces) that explore themes in teaching and learning. As they do so, they each develop a creative piece in the medium of their choice. The creative pieces are presented in a public forum presentation at the end of the course.

The intentions of the course are two-fold; that students think critically about how narratives work within the broader culture and that they learn creative ways of telling a story. In relation to the former intention, Said (1993) has argued, "The power to narrate, or to block other narratives from forming and emerging, is very important to culture and imperialism, and constitutes one of the main connections between them" (pp. xii-xiii). Thus a commitment to social justice can involve critical self-analysis of the internalization of domination, colonialism, and unjust discourses. Sawyer and Norris (2013) call for a process in schools to allow those involved the opportunity to become 
conscious of the internalization of oppression. We believe that teachers, even those working from a social justice perspective, may be engaged in action at the expense of personal reflection and analysis and risk re-enacting oppressive narratives without being aware of it; however, through reflection and analysis, action is informed, discourse can be reframed and language reconsidered.

Each professor teaches the course independently and our narratives below explore the various ways that we use our specialist backgrounds (language and cultural theoryElizabeth, community psychology-Morgan, visual art-Heather). Following this we discuss the strengths and challenges of the course including the assignment of grades.

Because ED 6394 is offered as an optional culminating course for students on the allcourse Masters program it is heavily subscribed. The majority of the students are practicing teachers and class-sizes range from approximately ten to 20 students. Students reflect that they find the course a powerful way to tie off the final threads of a graduate degree or to draw together the strands of a life in progress.

There are two assignments for evaluation: a portfolio and a project. In their portfolios students document their week-by-week engagement with readings, films, fieldtrips and course discussions, as well as the development of their projects. The portfolio might include samples of work that strikes them, a journal or blog in which they discuss course and outside readings, viewings, etc. (sometimes small groups choose to do this collectively as a blog or Facebook group), drafts of their own work, and so on.

The completion and public presentation of the final project or body of work involves many students in thinking about their own journeys through life and through education. Some focus on family history while a few choose to tell narratives about their community or a public figure or to explore other themes relating to Education. Whatever medium a student chooses to work in, she is telling a story. Therefore, the mark is partly based on how successful the student is at telling her story. We suggest something in the range of three to five sustained pieces of writing (ten or more pages each), five to ten minutes of polished tightly edited sound, drama, music, documentary or video, three to five substantial art pieces or eight to ten shorter or less substantial pieces in any medium. The student may also be working towards a longer project such as a book or full-length documentary. In this case we negotiate individually what aspects of it will constitute the project.

\section{Elizabeth: Some questions of form and content}

After the 2011 earthquake and tsunami in Japan I heard a radio report from a ruined fishing village. In the midst of devastation and death, rescue workers had placed a box to hold the photos and letters they found as they worked. Even at such a desperate time - perhaps especially at such a desperate time - they knew that those items might be terribly important for the survivors. Later I heard another report of photos, diaries and letters from Japan washing upon the beaches of British Columbia. A plea went out for finders to save them so they could be returned to survivors. We place a high value on personal stories and images.

It is widely accepted in the field of Education that there are multiple intelligences: spatial, linguistic, logical-mathematical, technological, bodily-kinesthetic, naturalistic, musical, interpersonal and intrapersonal (Gardner, 1999). However, only a couple of these are truly valued by most schools: the logical-mathematical and the linguistic. We 
also recognize that students should be able to represent knowledge in multiple ways using all sorts of different media. Yet teachers often struggle to know how to recognize and develop diverse forms of intelligence and to teach and support the use of various art forms and mediums to produce creative representations of knowledge. One reason is that they themselves have not been taught in ways that enable them to do so. This course was designed to give teachers a chance to explore stories that are important to them through creative means, using intelligences and technologies that they do not normally use or in which they want to develop their skills.

At least this was my original goal when I developed the course. It would provide a place for more personal storytelling than is usual in the university and a space for learning new mediums and skills that teachers could apply to their own teaching. Every time I teach the course the students surprise me by coming up with new interpretations of the course's scope and possibilities: science and math teachers challenging themselves to learn to sculpt and paint, French immersion teachers creating French language story books, a novelist and a poet who won awards for work they developed in the course, a film about the dialects of Newfoundland's southern shore and another about camping as experiential education. Film, photography, art, music, crafts, and stories. Sometimes I try to constrain them: it's difficult to know how to mark things like quilts and scrapbooks in a graduate course in Education - but the students' ingenuity always comes through. For example, at one point I wouldn't allow scrapbooks because I thought they didn't allow enough scope for creative exploration. A student argued with me that a scrapbook could be just as richly creative as any other approach. It was the artistry that mattered, she said, not the form or the medium. I didn't back down but when I saw her final project I laughed. She had produced wonderfully creative scrapbook pages on twenty individual canvases since she couldn't do them in a scrapbook. And scrapbooks have been allowed since then.

\section{Morgan: A Four-Part Harmony}

I agree with Peavy (1997) that "[a] life well lived... is more like a work of art, more like a poem or a dance" (p. 10). Teaching this course has supported both students' and my own engagement with the 'narratives of art' that comprise our lives. Here is my four-part narrative of teaching this course that draws from multiple commitments community and counselling psychology; social justice and democracy in education; and critical, participatory, narrative, strengths-based and arts-informed forms of inquiry.

\section{Mindful Self-Study}

Students panicked. It was week two and most students had not chosen a project topic. Maybe this is the perfect place to start, I suggested, perhaps it's okay to slow down and listen for a while. They laughed. (instructor journal, May 2012)

The title of John Irving's book on Michelangelo's life, "The Agony and the Ecstasy" relays an artist's life fraught with real struggle and immeasurable reward. Initially, the course is an invitation to wrestle with oneself. The creative narrative lens invites students back to themselves - to start from where they are; to listen, sense, and breathe, letting things rise to the surface. Not a graduate course of neatly organized and ready-made plans, students jostle to shift their navigation tools of learning towards mindfulness, self-study, curiosity and letting go. They realize this course is not about 
playing it safe or playing by the 'rules' of learning they have been accustomed to. Thankfully, with few exceptions, students come to genuinely, and many passionately, embrace this opportunity using this course as a space to really thrive, both personally and professionally.

“...[this] was the most eye opening learning experience of my life.... this course challenged me to look at and learn about myself. It was the most beneficial thing I have ever done...." (student e-mail, Aug. 2012)

\section{Not Just Any Story}

In class, we talk about how 'we lived storied lives', and yet, we can take these stories for granted. We can forget whether we are first authors or whether someone else and/or our culture wrote most of their prose. As a learning community, we explore stories we want to live by; the narratives we desire to author and own (White \& Epston, 1990) making explicit the power narratives have to foster or constrain individual and collective agency. The breadth of student topic choices demonstrates that education is life weightlifting, grandparents, students with autism, having cancer, rural teaching, studentteacher relationships. The realization that a story can be told in many different ways takes on new meaning for most students during the course. In part, we discuss the politics of this work. We consider our non-neutrality as authors. During class we explore the construction of narratives from different theoretical perspectives (i.e., critical, hermeneutic) so that students can better identify and choose particular voice(s) or points of view(s) in the creation of their narratives. For many students this is the most challenging part of the course - the stepping back to explicitly name their lenses on life; for many, however, this is also the place where they find a new freedom, agency or sense of transformation they had not previously felt, as noted in the student excerpt below.

...I was spending...time... on the negativity of my experiences... not how it... transformed me.... my story has led me to understand and develop strengths within myself ... through a strengths-based lens.... [I] also cross[ed]...into critical theory... Seiler says, "Critical theory teaches that knowledge is power...." ...This was certainly the case for me, and my narrative (student artist statement excerpt, 2013).

\section{Deepening Democracy}

Becoming a deep democracy as a class involves "creating the conditions through which...[we]...experience the pleasure, anxieties and responsibilities of democratic life" (Gude, 2009, p. 7-8). How do we enjoy, care for and challenge each other at the same time? How can we feel agency, belonging and voice? In this course fostering 'deep democracy' seems particularly valuable. Authoring creative narratives invites greater vulnerability and awakening to multiple facets of self and lives. I notice hurt can occur more easily in class. I witness the profound impact students' sense of care and affirmation for one another have in shaping the tone of the class. We are shaping each other's construction of stories through gesture and word. If someone is absent they are often discussed and missed, because if, and only if, we are fortunate, we have each become indispensible to the class; perhaps this is the best of deep democracy or a sign, at least, of its presence.

"I loved the honesty and emotion expressed across your narratives. I am touched 
and changed as a teacher because of your work." (written student to student feedback, July 2013)

As the instructor, I try to invite a learning democracy through co-constructed curriculum (of readings and resources) and via pedagogies of co-facilitation (in class), co-evaluation (of final projects), peer mentoring (during the course) and continuous community building (in large and small groups). These kinds of democratic processes further highlight the freedom and responsibility that come with becoming the authors of our lives, as students and teachers, in relation to one another.

\section{Pedagogies of Imagination}

As a class, the goal is to communicate with each other through languages of the arts and academic discussion. Groups of students take turns facilitating the first hour of each class via forms of experiential, arts-informed learning. They are asked to lead through imagination. They engage the class in the main themes articulated in the week's readings through poetry writing, collage, song, drawing, dance and so forth. This allows students to connect to academic texts through multiple ways of knowing so they can better feel and process their ideas and impact. Of equal intent during this experiential work is to have fun, experiment with different forms of art-making, gain project ideas, and take creative class pedagogies back to K-12 classrooms. Many times, students come to class excited to share how they engaged their own students using the arts, based on something they experienced in class the week before. In exploring the art-maker within themselves, many students gain more courage and confidence to engage the art-maker in their own students; this creates a wider circle of benefit and change in educational settings.

\section{Heather: Amazing Work from Personal Stories...}

I am an arts specialist, and am a relative newcomer to teaching the course. In general I love how students locate meaning in the combination of narrative approaches and creative work. I frequently use large group discussions to help us think through the readings, to check in about the on-going development of the students' projects and for the development of creative work including, occasionally, if it feels right, my own. Here's how it might work: a student arrives at class with a new poem, but she's stumped for a title and asks for our help. She reads a description of a morning spent with a much loved person, but then, with one line, she makes us shiver - something has happened to make her question cosmic processes and meaning... Using artful contrast her poem has shaped our emotional response and enabled us to encounter ambiguity and complexity. Afterwards in our discussion someone suggests that this was the most powerful line and might also be the title and the student immediately agrees - with our careful listening and validation she's recognized the power of the particular image she's crafted. We've served as a supportive sounding board - a place to 'workshop' her developing creative piece.

Because many students are thinking about their own life stories, and perhaps because of the nature of the relatively small group, some disclose painful memories. This is a challenge and there are no guaranties that the individual won't regret such sharing; however, I've seen amazing, polished and beautiful work grow from personal stories. Reflecting on deeply felt experiences students take great care in the aesthetic shaping of their creative products. In one instance a participant informed the class at the beginning 
of the term that she wanted to use the course to further her process of coming to terms with the death of a family member a few years previously. This was an extremely high expectation, but nevertheless, she persevered. She wrote moving poetry, experimented with a zine format suggested in one of the readings, and finally focused on the creation of sophisticated imovie. In the latter she made references to ideas and metaphors from the course readings, while thoughtfully narrating her development as an educator against a visual backdrop of the various rural and urban communities where she had taught. She touched on the significant losses she'd suffered, but these weren't the main story. Rather like Shields (2005), who explores narrative inquiry as "a journey of (re)connection with myself through (re)visiting and (re)constructing stories from my past that cross time and situation and speak to who I am becoming in the present" (p. 186), the student focused on how through looking back she was able to move forward. When she showed her imovie during the final public forum presentation, dozens of her friends and school colleagues attended to witness and support her remarkable achievement. From my perspective she took a significant risk but was ultimately very successful in telling her story in a creative way while also pointing to the manner in which narratives work within the broader culture.

\section{Strengths and Challenges of the Course}

Heather

Holistic learning through crafting personal stories using the strategies of the creative arts can make a deep and lasting impact on students. Nevertheless, I've found that while some students are very much taken with the creative possibilities of storytelling they may pay less attention to the manner in which narratives work within the broader culture. Therefore I continue to seek new materials that model the two-fold intensions of the course to help me in this regard.

\section{Morgan}

While many students indicate this was the best course they have taken in their program, for some it was also the hardest. While the arts and arts-informed ways of knowing open students onto a larger canvas of possibilities for reflection and expression, such unbridled potential for expression can feel daunting and uncomfortable, particularly in the early stages of the creative process. Moving away from logical-cognitive sensibilities to neatly manage and control their creative process and project can be lessons hard won. Equating what story to tell with trying to find the best story to tell, or being concerned about whether the story of their interest is good enough to tell, can be an internal struggle demanding students' time. Even when I support students to 'start from where they are' knowing that each student brings different experiences, skills and resources to their creative narrative work, this course demands a coming together and integration of many sensibilities and abilities. Students are called to be creative and critical, free-flowing and organized, (en)visioning and pragmatic/realistic, personal and performers, solo and collaborative, theoretical and experiential, and process and product oriented. Across this "crisis" of narrative creativity - in the context of the Chinese meaning that signifies both danger and opportunity - it is easy to acknowledge, as an instructor, that students are the heart and inspiration of this course. Students demonstrate courage, tenacity and openness. They construct moving, telling narratives that beautifully 
illustrate how we shape, and are shaped by, the many faces of education in our lives. Thanks to Elizabeth, as the creator of this course in our graduate program, students and instructors can experience some of the best of teaching and learning.

\section{Elizabeth}

I still struggle to evaluate the work the students produce. Most of them are not artists, writers, craftspeople, filmmakers or musicians so it seems unfair to evaluate them on the usual kind of criteria for such works. I try to give students the benefit of the doubt, to gage the scope of the work and thought through examination of the portfolio at several points during the term, and to mark generously and holistically, reserving the highest marks for students who have clearly invested a great deal in their work. I also give the students detailed comments on their ongoing projects and portfolios throughout the term, but actual marks only at the end of the course. Some students resist this idea at first because they have learned that good teaching involves building blocks, with marks given for each block completed so learners "know how they are doing" - an approach that works well for some kinds of learning but is not so appropriate for evaluating a creative process. I am never quite happy about the marks and would prefer for the course to be pass/fail but so far this has not been the decision of the faculty. There are problems with a pass/fail model too as some students may need marks for scholarship applications and other purposes and also want recognition of hard work and talent. There is no ideal solution. I think that the best we can do is try to engage closely with the students so we can indeed recognize both hard work and talent.

\section{Speculations for the Future}

The conversations involved in the writing of this paper have allowed us to enrich our understanding about how each of us works with the opportunities provided by Biographical Explorations. This is important to the evolution of our individual interpretations of it. However, regardless of who teaches the course we speculate that it will continue to have a powerful relevance in our graduate program because it involves participants with creative approaches to knowledge production and encourages them to reflect critically on the power of stories.

\section{References}

Gardner, H. (1999). Intelligence reframed. Multiple intelligences for the 21st century. New York: Basic Books.

Gude, O. (2009). Art education for democratic life. Art Education, 62, 6-11.

Irving, J. (1961). The agony and the ecstasy: A biographical novel of Michelangelo. New York: Penguin.

Peavy, V. (1997). Sociodynamic counselling: A constructivist perspective. Bloomington, IN: Trafford Publishing.

Said, E. (1993). Culture and imperialism. New York: Alfred. A. Knopf. 
Sawyer, R. \& Norris, J. (2013). Duoethnography: Understanding qualitative research. New York: Oxford University Press.

Shields, C. (2005). Using narrative inquiry to inform and guide our (re)interpretations of lived experience. McGill Journal of Education, 40(1), 179-188.

White, M., \& Epston, D. (1990). Narrative means to therapeutic ends. South Australia: Dulwich Centre. 